\title{
Is the suckling period and application pattern relevant for fluazuron against tick infestation in cows and their suckling calves?
}

Gonzalo Suárez ${ }^{1 *}$, Diego Robaina ${ }^{1}$, Agustina Muela² ${ }^{2}$ Saporiti Tatiana ${ }^{3}$, Florencia Puigvert ${ }^{2}$, Silvana Alvariza ${ }^{1}$ and Lucia Pareja²

\begin{abstract}
Background: Fluazuron is a chitin synthesis inhibitor administered as a pour-on formulation in cattle for tick control. This study analyzes under endemic tick infestation, the incidence of the pour-on application pattern on the plasma levels of fluazuron in calves and cows in the lactation period of the beef cow. Two hundred and ninety-two beef cows around parturition were treated with a commercial pour-on formulation of fluazuron at a rate of $2.5 \mathrm{mg} / \mathrm{kg}$ of body weight. A total of 4 treatments were carried out on days $0,32,77$, and 117 . At each administration time, the cows were grouped according to the pour-on administration pattern: long $(\sim 60 \mathrm{~cm}$ pour-on application surface) and short ( $\sim 30 \mathrm{~cm}$ pour-on application surface). Fluazuron levels in cows and calves plasma were determined before the third and fourth application for each subgroup $(n=10)$ by HPLC-MS/MS. During the entire study, cow-calf pairs were maintained under field conditions and qualitatively examined for tick infestation on the day of each treatment. Both treatments (long and short) schemes were designed to prevent the annual persistence of ticks.
\end{abstract}

Results: No animals with presence of ticks were identified during the first 117 days of the study, except for three cows and one calf at the time of the third application (day 77). There were no differences after 40 days (day 77) post-treatment of the second application ( $30 \pm 5 \mathrm{ppb}$ vs. $28.5 \pm 12 \mathrm{ppb}, p>0.05$ ) and 45 days (day 117) after the third application ( $147 \pm 55$ ppb vs $140 \pm 46 \mathrm{ppb}, p>0.05$ ) between groups of cows treated with the long or short pour-on application, respectively. Plasma concentration of fluazuron at second and third application was increased (3.3 and 2.9 times, respectively) in calves under free suckling compared to cows. Nevertheless, both groups of cows and calves showed a significant increase in plasma concentration of fluazuron between times ( 4.9 times, $p<0.0001$ and 2.8 times, $p<0.0001$, respectively). In both groups, tick prevalence was $0 \%$ throughout the trial, except for day 77 , which reached $1 \%$.

Conclusions: The main conclusions of this study were the following: 1) Different administration patterns (long vs. short) did not differ in plasma levels of fluazuron.; 2) Given that only the cows were treated and lactating calves presented higher plasma levels of fluazuron than cows, passage through milk appears to be relevant and possibly due to a cumulative effect and continuous drug intake.

Keywords: Cattle, Benzoylphenyl ureas, Milk, Residues, Rhipicephalus microplus

*Correspondence: suarezveirano@gmail.com

${ }^{1}$ Unidad de Farmacología y Terapéutica, Departamento Hospital y

Clínicas Veterinarias, Facultad de Veterinaria, Universidad de la República,

Montevideo, Uruguay

Full list of author information is available at the end of the article

\section{Background}

Tick infestations constitute one of the major problems in livestock production in Uruguay and South America [1, 2]. The use of acaricides in Uruguay has 
been the main tool for tick control [3]. In control programs of ticks, drug administration requires a strategic dosage plan with established times according to the residuality of the drugs or depending on the establishment's tick control or eradication program [4]. In tick control programs, dip acaricides must be used with organophosphates, pyrethroids, and amidines, while with injectable and pour-on applications, macrocyclic lactones, fipronil, and fluazuron are the most relevant [5]. Resistance has been reported for all the aforementioned drugs, except for fluazuron, which has no practical in-vitro tests for its detection [6].

Fluazuron is responsible for inhibiting chitin synthesis on immature ticks, preventing them from achieving adult stages. Insect growth regulators, such as fluazuron, could be responsible for the long-term response given the delayed effect that this type of compounds have on insect's life cycle [7], reducing the number of immature life stages of Rhipicephalus microplus (R. microplus).

The application of pour-on formulations of fluazuron in the initial period of lactation generates uncertainty about the levels reached in cows or their lactating calves. Likewise, the persistence levels or the elimination rate of fluazuron in lactating cow beef are not clear [8]. Concentration levels due to digestive absorption in lactating calves are also not reported. Furthermore, differences in the practical application technique at the field level, using different empirical recommendations in the topical administration of the product, varying the extension on the application surface, but maintaining the dose, remains uncertain.
Therefore, the efficacy and associated benefit of the fluazuron poured preparation as a tick control alternative in lactating cows needs to be documented. The objective of this study was to determine, in endemic tick infestation, the incidence of the application pattern of fluazuron pour-on on the plasma levels in cows and calves in the lactation period of the beef cow.

\section{Results}

The prevalence of ticks at the beginning of the experiment (day 0$)$ was $1 \%(3 / 292)$, as expected by the epidemiological model described for Uruguay. In the following evaluations (32, 77, and 117 days), no animals with presence of ticks were identified, except for three (in short group $0.7 \%$ [1/145] and in long group 1.3\% [2/147]; $p>0.05)$ and one calf at the time of the third application (day 77). The infestation rate was not different (Odds ratio $\left.0.5, \mathrm{CI}_{95 \%}[0.008,9.79]\right)$ between the two application surfaces groups throughout the evaluation periods.

The individual levels of fluazuron in cows determined prior to the third and fourth repeated application for each subgroup $(n=10)$ are presented in Fig. 1. There were no differences after 40 days (day 77) post-treatment of the second application $(30 \pm 5 \mathrm{ppb}$ vs $28.5 \pm 12 \mathrm{ppb}$, $P>0.05$ ) or at 45 days (day 117) after the third application $(147 \pm 55 \mathrm{ppb}$ vs $140 \pm 46 \mathrm{ppb}, P>0.05)$ between the groups of cows treated with the long or short pouron application, respectively. In view that the cow groups (long vs short) did not present statistical differences, it was all considered as a global cow group. Forty days after the second administration (day 77), the average

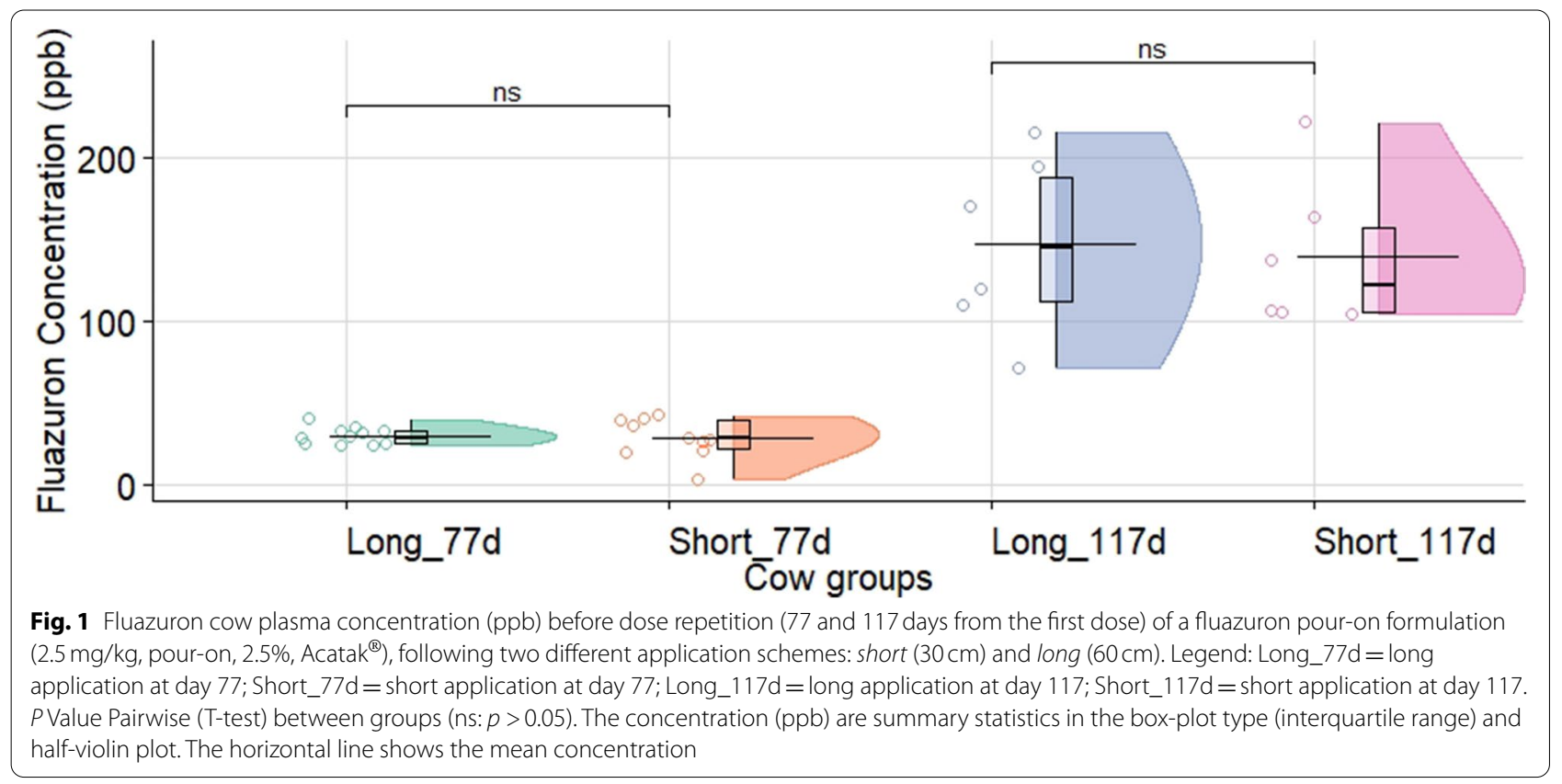


concentration ( \pm standard deviation) for the global cow group and calves were $29.3 \pm 8.9 \mathrm{ppb}$ and $147 \pm 43 \mathrm{ppb}$ $(P<0.0001)$, respectively (Fig. 2$)$. The application of the third repeated treatment and the determination of the concentrations 45 days later (day 117) increased the average concentration reaching $143 \pm 49 \mathrm{ppb}$ and $417 \pm 87 \mathrm{ppb}(P<0.001)$ in the treatments of global cow and calf groups, respectively (Fig. 2). Plasma concentration of fluazuron prior to the third and fourth application increased 3.3 and 2.9 times (respectively) in calves under free suckling vs. cows (Fig. 2). Nevertheless, the global cow group (4.9 times; $P<0.0001)$ and the calves $(2.8$ times; $P<0.001)$ showed a significant increase in plasma concentration of fluazuron, between 77 at 117 days (Fig. 2).

\section{Discussion}

The bioavailability of a drug is directly dependent on its rate and degree of absorption at the administration site. Factors that affect the absorption of the drug, including patterns for the pour-on application, will directly affect the bioavailability of the drug. Our results suggest that the drug dispersion pattern long vs. short does not represent a relevant variable when the correct dose is administered. The topical absorption of the pour-on formulation can be explained through the Fick law of diffusion, which established that the drug molecules move according to the concentration gradient from a higher drug concentration to a lower one until equilibrium is reached [9]. Although in our study we doubled the absorption surface (line of application pass the $30 \mathrm{~cm}$ to $60 \mathrm{~cm}$ ), we did not modify the dose, therefore the concentration was decreased per contact surface, which possibly determined that the passive diffusion of the drug was not significantly modified.

When redosing lipophilic drugs such as fluazuron at established times, not only the pharmacokinetic profile on the dam is affected, but also the plasma levels on lactating calves. After pour-on treatment at $1.5 \mathrm{mg} / \mathrm{kg}$, the mean plasma levels remained stable between 9 and 35 days after treatment, ranging from 35 to $41 \mu \mathrm{g} / \mathrm{L}$ and declined at about $7 \mu \mathrm{g} / \mathrm{L}$ at 16 weeks [10]. Using the same dose and formulation, but from a single administration and during a short period, Ferreira et al. [11] reported lower plasma concentration values. In our study, the dosing interval was set at 4-6weeks following the manufacturer recommendations and the governmental guidelines on tick control for Uruguay, which could explain the higher concentration levels of fluazuron found in cows and calves. In addition, we used a dose of $2.5 \mathrm{mg} /$ $\mathrm{kg}$ as recommended by the manufacturer. Both the dosing period and the higher dose could explain the higher plasma levels for fluazuron found in our study. The Committee for Medical Products for Veterinary Use [12] issued a Summary report on fluazuron pharmacokinetic behavior, with fluazuron being excreted via cow's milk to calves, resulting in higher plasma and fat residue levels in calves compared to the ones in cows.

Accumulation is usually considered on plasma, overlooking the effect on tissues with poor blood perfusion [13], leaving the explanation for drug accumulation on lactating animals relegated as to whether accumulation

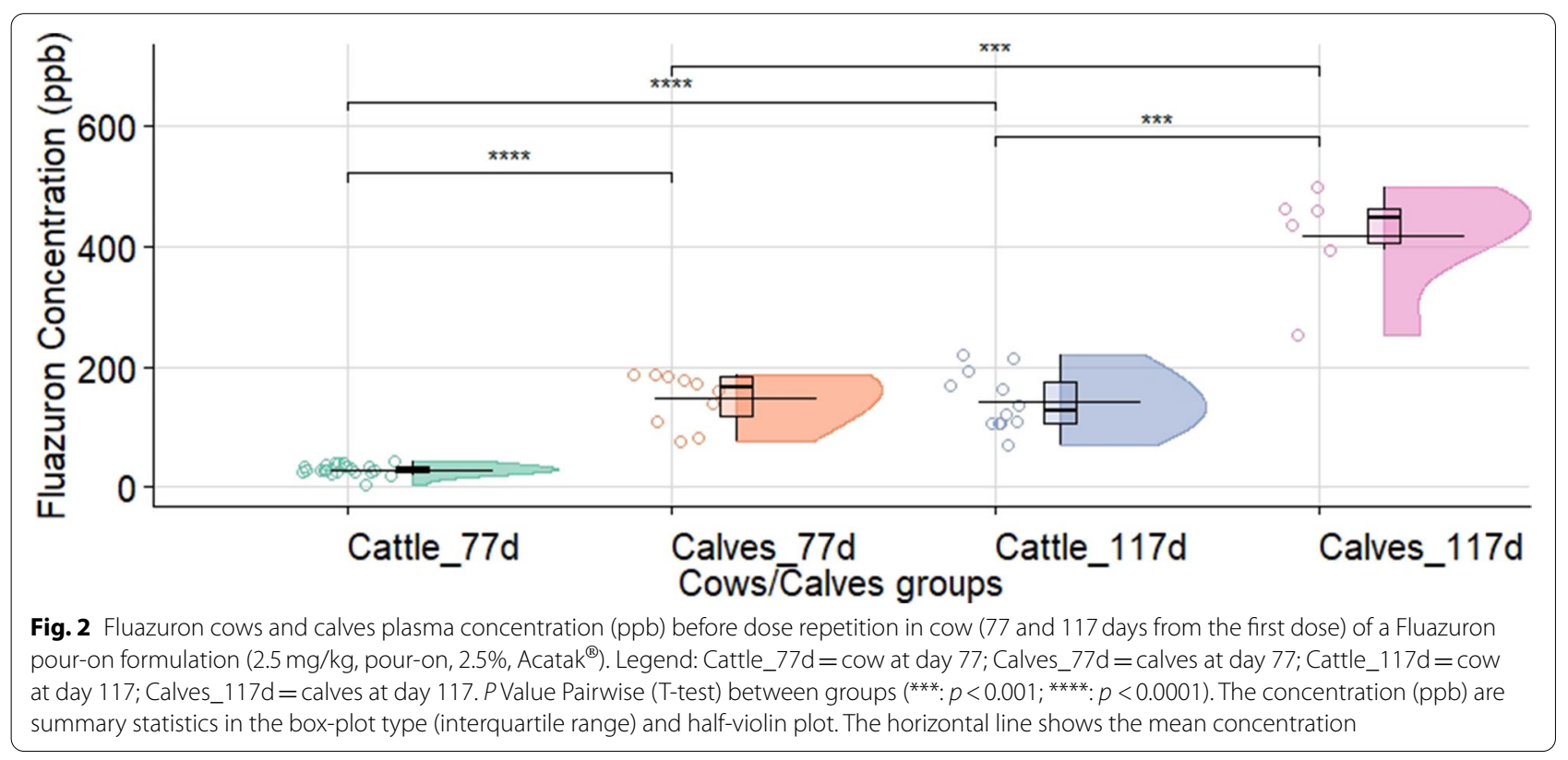


occurs and the possible impacts of such process. According to [12], a steady state between absorption and elimination was observed for 3 to 4 weeks after treatment. When a single dose of fluazuron is administered topically to cattle, the depletion from plasma is slow, with an elimination half-life of 10.5 weeks. Therefore, multiple doses could lead to drug accumulation both in the cow and the calves. As reported by [12], multiple treatments with 12-week intervals did not lead to the accumulation of fluazuron residues.

The greater accumulation of this acaricide in calves concerning lactating cows and the increase between subsequent administrations, could be explained by the continuous intake via the digestive tract through milk. Different authors document the importance of licking in topical administrations and the relative importance of the dermal and oral routes in the removal of drugs from the skin $[14,15]$. We ruled out the licking effect since at the time of application we made a quick visual inspection and determined a null licking behavior in the first hours after applying all treatments (Unpublished Data). As stated by [16], the excretion of parent compounds and/or their metabolites from plasma into milk is a complex process related to physicochemical properties and membrane interactions. Fat content is one of the main factors that contribute to the concentration of hydrophobic drugs into milk $[17,18]$. Given the lipophilic characteristic of fluazuron, fat and milk residue levels are expected to be higher than in plasma.

In this study, the prevalence and burden of $R$. microplus found in the animals are consistent with the data provided by the conceptual epidemiological model described by [1] for Uruguay. Under ideal temperature and relative humidity conditions $\left(27^{\circ} \mathrm{C}\right.$ and over $\left.80 \% \mathrm{RH}\right)$, the first generation of ticks takes place between August and October, while the second generation appears from December to February. The tick populations parasitizing cattle is higher in the first generation, with an average of 25 ticks per animal. Considering that the study was carried out on a farm with a background of tick infestations in previous autumns and that the prevalence was lower than expected by the epidemiological model, we can consider that the concentration levels of fluazuron in the animals were enough to prevent the development of the parasitic cycle of the tick.

The rational use of drugs is crucial in food-producing animals because of the potential adverse effects of drugs that appear as residues in edible tissues [19-21]. Milk excretion needs to be quantified in order to understand the pharmacokinetic changes that could occur during the suckling period and the impact on parasites control and drug residue levels, especially on parasites with high health impact such as $R$. microplus. Further studies are needed to quantify milk excretion of fluazuron under pour-on administration on lactating cows. Achieving a pharmacokinetic model for this excretion route is the first step in understanding the use of this chemical tool for tick control around parturition.

\section{Conclusions}

The main conclusions of this study were the following: 1) Different administration patterns (long vs. short) did not differ in plasma levels of fluazuron; 2) Given that only cows were treated and lactating calves presented higher plasma levels of fluazuron than cows, passage through milk appears to be relevant and possibly due to a cumulative effect and continued drug intake.

\section{Methods \\ Study location}

The study was conducted from August to December 2019 (end of winter and beginning of summer) on a farm located in Artigas, Uruguay, South America $\left(30^{\circ} 06^{\prime}\right.$ South, $57^{\circ} 04^{\prime}$ West). The farm has a history of tick and use of all approved drugs (Ivermectin, Fipronil, Amitraz, or Fluazuron) for the control of $R$. microplus. Animals were not treated with acaricides in the 60 days previous to the fluazuron treatment. Tick infestations were present in a very low number of animals on the farm prior to the beginning of the study. The prevalence was as expected for the period selected for the trial, corresponding to the first generation of ticks within the epidemiological model of the country [1]. Rainfall during 2019 (January to December) was $1440 \mathrm{~mm}$, and the minimum and maximum temperatures were $4.6^{\circ} \mathrm{C}$ (July) and $30.9^{\circ} \mathrm{C}$ (October), respectively.

\section{Experimental design}

Two hundred and ninety-two beef cows (Hereford) around parturition were treated with a commercial pouron formulation of fluazuron (fluazuron $2.5 \%$, pour-on, Acatak Pour-on ${ }^{\circledR}$, Novartis, Brazil) at a rate of $2.5 \mathrm{mg} /$ $\mathrm{kg}$ of body weight. A total of 4 treatments were carried out with a dosing period set in a range of 32 to 45 days. At the administration time, two different patterns for the pour-on application were randomly tested and used as a grouping variable: long $(\sim 60 \mathrm{~cm}$ pour-on application surface according to the recommendations on the label of the surface to be covered by the product, $n=147$ ) and short ( $30 \mathrm{~cm}$ pour-on application surface [half surface], $n=145)$. The calves remained free of antiparasitic treatment. Throughout the study, cow-calf pairs were kept in the same paddocks and under field conditions (native grasses). Both treatment schemes were designed to prevent the annual persistence of ticks. A control group was 
not included because the farm was in a global tick control strategy.

\section{Data recovery}

\section{Quantitative analysis of tick infestation:}

All the cows and calves in the study were qualitatively examined for tick infestation on the day of each treatment (day 0, 32, 77 and 117). Each animal was examined for the presence of ticks (adult engorged female ticks; $4.5-5 \mathrm{~mm}$ of diameter) on the head, ears, neck, back, perineum, and tail [22]. A careful examination was carried out in $10 \%$ of the animals (randomly selected), which included the examination of the belly and legs. Tick presence was recorded as a binary variable (presence/absence of ticks). An animal showing one or more ticks was considered a positive case (presence), while animals free of ticks were considered as negative cases (absence).

\section{Fluazuron analytical procedures}

Before the third and fourth application (days 77 and 117 , respectively), blood was taken from 10 animals from each group of cows (long and short) and 10 calves randomly (using heparinized tubes).

Fluazuron concentration in plasma was determined by HPLC-MS/MS, based on the procedure validated by our group with acceptable accuracy according to the guidance document on analytical quality control and method validation procedures for pesticide residues analysis in food and feed from the European Commission [23]. Matrix-matched calibration curves in the range from 5 to $1000 \mathrm{ppb}(\mu \mathrm{g} / \mathrm{kg})$ were established using least-squares linear regression analysis and correlation coefficients $(r=0.99)$ and back-calculated concentration residuals below $20 \%$. A limit of quantification (LOQ) of $5 \mathrm{ppb}$ was defined as the lowest measured concentration with a relative standard deviation below $20 \%$ and an absolute recovery $\geq 70 \%$. Concentration values below the LOQ were not considered in the analysis of experimental data.

\section{Statistical analysis}

The prevalence (\%) of ticks was determined as the ratio of the number of existing cases during a certain period of time and the population at risk during that specified period [24]. The plasma concentration data are reported as arithmetic mean $\pm \mathrm{SD}$. Differences between cows groups (long or short) at each time were analyzed for statistical significance using the independent samples t-test. Since the long and short groups did not present statistical differences, they were considered a single group of cows (global cows group). The differences between calves and the global cows group within and between times were analyzed for statistical significance using the independent samples t-test, previously applied Shapiro-Wilks test and graphical method to check normality. Statistical analyses of differences in the prevalence rates between groups were performed with Fisher's exact test. A $p$-value $<0.05$ was considered statistically significant. The statistical analysis was performed using R Statistical Software (version 4.0.3 [2020-10-10]) [25].

\section{Abbreviation \\ HPLC-MS/MS: High Performance Liquid Chromatography Tandem Mass Spectrometry.}

\section{Acknowledgements}

The authors wish to thank the Facultad de Veterinaria, Universidad de la República for allowing this trial to be carried out; and Agencia Nacional de Investigación e Innvación (ANII) for funding the trial. The authors wish to thank the invaluable support of the people of the farm for assisting in Animal Management.

\section{Authors' contributions}

GS conceived, designed, and supervised the project. DR and GS performed the experiment and analyzed the data. AM, FP, and LP determined fluazuron concentrations. TS contributed on field experiments. GS, DR, and LP wrote the manuscript, with contributions from SA. All authors reviewed the manuscript. The author(s) read and approved the final manuscript.

\section{Funding}

This study was funded by Agencia Nacional de Investigación e Innovación (ANII) from Uruguay under a project form Applied Research: Fondo María Viñas Modalidad I(FMV_1_2017_1_136809).

\section{Availability of data and materials}

The datasets used and/or analyzed during the current study are available from the corresponding author on reasonable request.

\section{Declarations}

Ethics approval and consent to participate

All methods were carried out in accordance with relevant guidelines and regulations. The present study was approved by the Comisión Ética en Uso de Animales (CEUA) of Facultad de Veterinaria-Universidad de la República, under protocol No. CEUA FVET-PI 506-1493294137. The study was carried out in compliance with the ARRIVE guidelines.

Informed consent was obtained from farm owners for including animals in the study.

\section{Consent for publication}

Not applicable.

\section{Competing interests}

The authors declare that the study was conducted in the absence of any commercial or financial relationships that could be construed as a potential conflict of interest. Authors do not have any competing interests to declare.

\section{Author details}

${ }^{1}$ Unidad de Farmacología y Terapéutica, Departamento Hospital y Clínicas Veterinarias, Facultad de Veterinaria, Universidad de la República, Montevideo, Uruguay. ${ }^{2}$ Grupo de Análisis de Compuestos Traza, Departamento de Química del Litoral, Cenur Litoral Norte, Universidad de la República, EEMAC, Ruta 3 Km 363, 60000 Paysandú, Uruguay. ${ }^{3}$ Unidad de bioquímica, Departamento de Biociencias, Facultad de Veterinaria, Universidad de la República, Montevideo, Uruguay.

Received: 6 April 2021 Accepted: 22 November 2021 Published online: 06 December 2021 


\section{References}

1. Fiel C, Nari A. Enfermedades parasitarias de importancia clínica y productiva en rumiantes: Fundamentos epidemiológicos para su diagnóstico y control. Segunda. Montevideo: Hemisferio sur; 2013. p. 0-752.

2. Molento MB. Avaliação seletiva de bovinos para controle do Rhipicephalus microplus. Ars Vet. 2020;36(1):001-2.

3. Miraballes C, Riet-Correa F. A review of the history of research and control of Rhipicephalus (Boophilus) microplus, babesiosis and anaplasmosis in Uruguay. Exp Appl Acarol. 2018;75(4):383-98.

4. Cuore U, Acosta W, Bermúdez F, da Silva O, García I, Pérez Rama R, et al. Tratamiento generacional de la garrapata: Aplicación de una metodología en un manejo poblacional para la erradicación de Rhipicephalus (Boophilus) microplus resistentes a lactonas macrocíclicas. Veterinaria. 2015:51(198):44-52.

5. Cuore U, Solari M, Trelles A. Current status of resistance and first diagnostic of multiple resistance Rhipicephalus (Boophilus) microplus tick simultaneously resistant to five drugs in Uruguay. SMVU Vet. 2017;53(205):13-9.

6. Reck J, Klafke GM, Webster A, Dall'Agnol B, Scheffer R, Souza UA, et al. First report of fluazuron resistance in Rhipicephalus microplus: a field tick population resistant to six classes of acaricides. Vet Parasitol. 2014;201(1-2):128-36

7. Holdsworth PA, Vercruysse J, Rehbein S, Peter RJ, Letonja T, Green P. World Association for the Advancement of Veterinary Parasitology (W.A.A.V.P.) guidelines for evaluating the efficacy of ectoparasiticides against biting lice, sucking lice and sheep keds on ruminants. Vet Parasitol. 2006;136(1):45-54 [cited 2016 Apr 18]. Available from: http://www.scien cedirect.com/science/article/pii/S0304401705005510.

8. Junquera P, Hosking B, Gameiro M, Macdonald A. Benzoylphenyl ureas as veterinary antiparasitics. An overview and outlook with emphasis on efficacy, usage and resistance. Parasite. 2019;26:26.

9. Neupane R, Boddu SHS, Renukuntla J, Babu RJ, Tiwari AK. Alternatives to biological skin in permeation studies: current trends and possibilities. Pharmaceutics. 2020;12(2):152.

10. Pronk MEJ, Schefferlie GJ. Fluazuron [internet]. The forty-eighth meeting of the Joint FAO/WHO Expert Committee on Food Additives (JECFA). Geneva; 1997. [cited 2021 Apr 5]. Available from: http://www.inchem.org/ documents/jecfa/jecmono/v39je09.htm

11. Ferreira TP, Lima IP, Magalhães VS, Avelar BR, Oliveira GF, Scott FB, Cid YP. Bioanalytical Method to Measure Fluazuron in Bovine Plasma and its Application in Pharmacokinetic Studies. Rev. Virtual Quim. 2019;11(3):1067-79.

12. EMEA. Committe for medical products for veterinary use: Fluazuron summary report. 2005. Available from: http://www.emea.eu.int.

13. Brocks DR, Mehvar R. Rate and extent of drug accumulation after multiple dosing revisited. Clin Pharmacokinet. 2010;7:421-38.

14. Laffont C, Bousquet-Mélou A, Bralet D, Alvinerie M, Fink-Gremmels J, Toutain $\mathrm{P}-\mathrm{L}$, et al. A pharmacokinetic model to document the actual disposition of topical ivermectin in cattle. Vet Res. 2003;34(4):445-60 Available from: https://hal.archives-ouvertes.fr/hal-00902759.

15. Toutain PL, Lees P. Integration and modelling of pharmacokinetic and pharmacodynamic data to optimize dosage regimens in veterinary medicine. J Vet Pharmacol Ther. 2004;27(6):467-77.

16. Shoop WL, Egerton JR, Eary CH, Haines HW, Michael BF, Mrozik H, et al, Eprinomectin: a novel avermectin for use as a topical endectocide for cattle, vol. 26; 1996.

17. Begg $E$, Atkinson $H$, Duffull S. Prospective evaluation of a model for the prediction of milk: plasma drug concentrations from physicochemical characteristics. Br J Clin Pharmacol. 1992;33(5):501-5.

18. Atkinson HC, Begg EJ. Relationship between human milk lipidultrafiltrate and octanol-water partition coefficients. J Pharm Sci. 1988;77(9):796-8.

19. Beyene T. Veterinary science \& technology veterinary drug residues in food-animal products: its risk factors and potential effects on public health. J Vet Sci Technol. 2016;7(1):1-7.

20. Teshome D. Review on rational use of veterinary antimicrobials and anthelmintics. Austin J Vet Sci Anim Husbandry. 2018;5(2):1044.

21. Whittem T, Whittem JH, Constable PD. Modelling the concentration-time relationship in milk from cattle administered an intramammary drug. J Vet Pharmacol Ther. 2012;35(5):460-71.
22. Holdsworth PA, Kemp D, Green P, Peter RJ, de Bruin C, Jonsson NN, et al. World Association for the Advancement of Veterinary Parasitology (W.A.A.V.P.) guidelines for evaluating the efficacy of acaricides against ticks (Ixodidae) on ruminants. Vet Parasitol. 2006;136(1 SPEC. ISS):29-43.

23. European Commission. European Union, 2002, COMMISSION DECISION 2002/657/EC, implementing Council Directive 96/23/EC concerning the performance of analytical methods and the interpretation of results, Official Journal of the European Communities, L 221/8, vol. 29; 2002.

24. Thrusfield M. Veterinary epidemiology. Equine Internal Medicine: Second Edition; 2004

25. RStudio Team (2020). Integrated development for R. RStudio.

\section{Publisher's Note}

Springer Nature remains neutral with regard to jurisdictional claims in published maps and institutional affiliations.
Ready to submit your research? Choose BMC and benefit from:

- fast, convenient online submission

- thorough peer review by experienced researchers in your field

- rapid publication on acceptance

- support for research data, including large and complex data types

- gold Open Access which fosters wider collaboration and increased citations

- maximum visibility for your research: over 100M website views per year

At BMC, research is always in progress.

Learn more biomedcentral.com/submissions 